\title{
Is Diuretic-Induced Hyperglycemia Reversible and Inconsequential?
}

\author{
Anil K Mandal ${ }^{1 *}$, Linda M. Hiebert ${ }^{2}$
}

\begin{abstract}
Background: Antihypertensive drugs including thiazide diuretics, beta blockers (BB), calcium channel blockers (CCB), reninangiotensin inhibitors or vasodilators produce elevated blood glucose (hyperglycemia) ( $>70-99 \mathrm{mg} / \mathrm{dL}$ ). Hyperglycemia is more common and severe with thiazide diuretics than with BB, CCB, ACEl or ARB drugs. Questions have been raised about the mechanism and risk of drug-induced hyperglycemia.

Method: We present here four patients treated with diuretics who developed hyperglycemia - fasting blood glucose (FBG) $>126$ mg/ $\mathrm{dL}(7 \mathrm{mmol} / \mathrm{L})$ diagnostic of diabetes. Three patients had hypertension and one, congestive heart failure (CHF). Three patients had no diabetes, one gave 8 to 10 year history of diabetes. One patient received no diuretic therapy and his glucose level was normal with insulin and oral hypoglycemic agent treatment. Subsequently, he became hypertensive and was treated with a thiazide diuretic but no antidiabetic agents. He then developed new-onset diabetes.

Results: All patients showed hyperglycemia above FBG criteria for diabetes. 2-hour postprandial blood glucose (2hPPG) was not diagnostic of diabetes in three patients. Two patients were prescribed antidiabetic therapy which was stopped with no worsening of hyperglycemia although diuretic therapy continued. In two patients diuretic was discontinued. Hyperglycemia abated in one, while in the other, hyperglycemia worsened requiring Glargine insulin.

Conclusion: Hyperglycemia is common in patients with hypertension or CHF treated with a thiazide diuretic alone or in combination with other diuretics. Although by definition the term new-onset diabetes may be used to connote hyperglycemia, in reality diabetes induced by diuretics is not diabetes as 2 hPPG does not usually exceed $200 \mathrm{mg} / \mathrm{dL}(11.1 \mathrm{mmol} / \mathrm{L})$, and patients show no evidence of any vascular complications. It may be more appropriate to define elevated glucose associated with diuretic "hyperglycemia" rather than new-onset diabetes. The real issue is that use of thiazide diuretics is imperative in blood pressure control especially in resistant hypertension. Even with new-onset diabetes, thiazide diuretics are commonly found to be safe, reducing risk of stroke, heart attack, and renal failure characteristic of uncontrolled hypertension. Therefore, risks of new-onset diabetes, induced by diuretic therapy, will be difficult to ascertain because of hypertension for which thiazide diuretic is widely used.
\end{abstract}

keywords: hyperglycemia, diuretics, diabetes

\section{Background}

Diabetes is a major cardiovascular risk factor, but drug-induced new-onset diabetes may not have clinical significance and should not be a major determinant when choosing a treatment for hypertension if the medication is necessary to reduce blood pressure[1]. A study found no difference in the number of patients who developed diabetes with different antihypertensive drugs, including diuretics and beta blockers as shown in Figure 1 [2]. Figure 1 demonstrates that all antihypertensive drugs may produce hyperglycemia although the risk of hyperglycemia varies. In the ALLHAT study, chlorthalidonetreated patients achieved the same primary end point results - fatal and nonfatal infarcts - as amlodipine or Lisinopril treated subjects despite the fact that an increase in serum glucose of 3 to $5 \mathrm{mg} / \mathrm{dL}$ and new-onset diabetes was more frequent in the

*Correspondence: amandal@med-spec.com

'Mandal Diabetes Research Foundation, St. Augustine, Florida

and University of Florida, Gainesville,Florida, USA.

Full list of author's information is available at the end of the article diuretic-based treatment groups. The investigators concluded that "there was no advantage to the use of Lisinopril compared with a diuretic despite the difference in new-onset diabetes". The use of alpha blockers does not increase serum glucose; but in the ALLHAT study, cardiovascular events were more frequent with an alpha blocker compared with a diuretic [3].

A group of investigators from Italy studied the outcome of new-onset diabetes in treated hypertensive subjects compared to those with previously known diabetes. They found that subjects in whom diabetes developed were exposed to diuretics, calcium channel blockers, and angiotensin converting enzyme inhibitors (ACEI) more frequently than those in whom diabetes did not develop as shown in Figure 2 [4].

The purpose of this communication is to present a few patients who were diagnosed to have developed diabetes during treatment of hypertension who were then placed on antidiabetic therapy. Withdrawal of antidiabetic therapy and treatment with potassium supplements did not result in worsening of hyperglycemia or appearance of overt diabetes.

(c) 2012 Mandal et al; licensee Herbert Publications Ltd. This is an open access article distributed under the terms of Creative Commons Attribution License

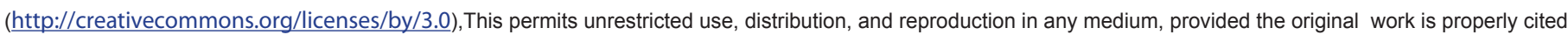



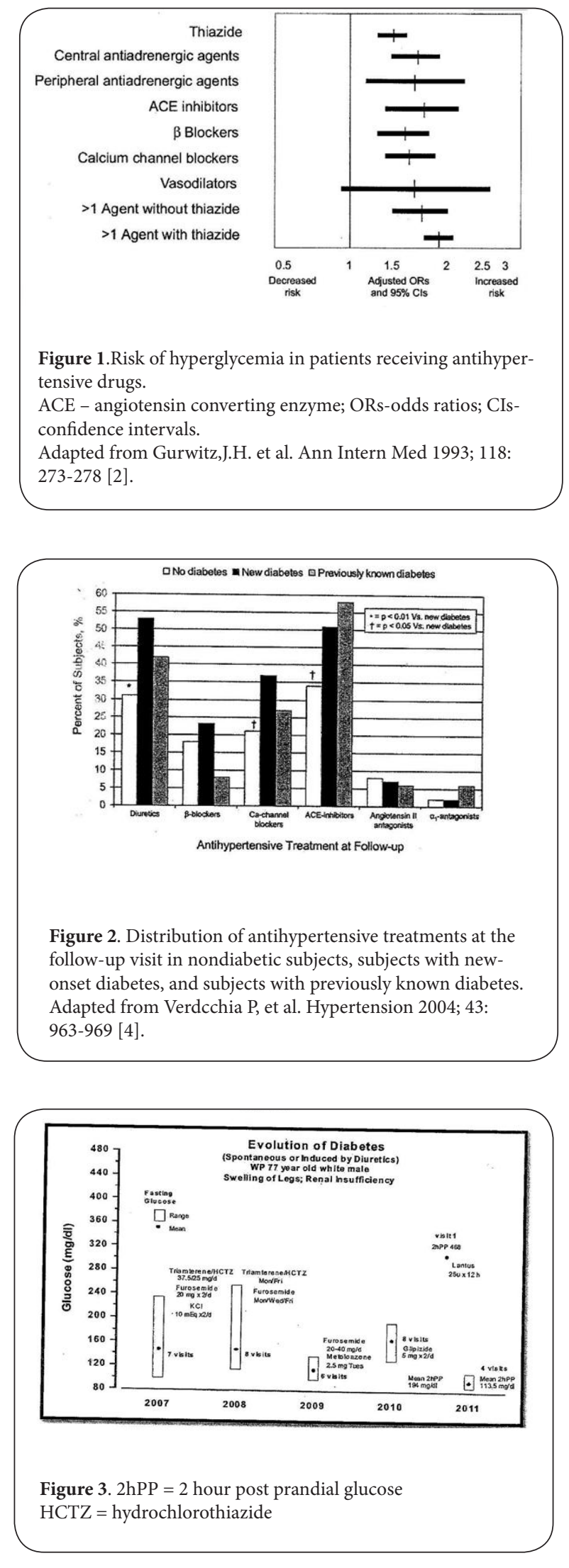

In addition, a patient is presented to demonstrate that diureticinduced hyperglycemia may occasionally lead to overt diabetes requiring insulin therapy.

\section{Methods and Results}

Overt diabetes is defined by a 2-hour post-load plasma glucose ( $2 \mathrm{hPPG}$ ) concentration of $\geq 200 \mathrm{mg} / \mathrm{dL}(11.1 \mathrm{mmol} / \mathrm{L})$ [5]. Hyperglycemia or new-onset diabetes has not been clearly defined. However, in this study hyperglycemia is defined by FBG above $126 \mathrm{mg} / \mathrm{dL}$ (7 mmol/L).

Patient \#1 - A 67 year old African American male was referred by a primary care physician and seen by the authors (AKM) in the office in November of 2011 for renal insufficiency. He gave history of hypertension for a long time and diabetes for nine months. He is a farm worker and is very active. Daily medication at the time of first visit consisted of hydrochlorothiazide (HCTZ) $25 \mathrm{mg}$, glimepiride $2 \mathrm{mg}$, Lisinopril $40 \mathrm{mg}$, pravastatin $80 \mathrm{mg}$, amlodipine $10 \mathrm{mg}$, metoprolol $100 \mathrm{mg}$, and allopurinol 300 $\mathrm{mg}$ all PO daily. During this visit he had a pulse of 66 beats/ min and sitting and upright blood pressures (BP) were 130/90 $\mathrm{mmHg}$. Otherwise his physical examination was normal. The only available laboratory data at this visit was decreased estimated glomerular filtration rate (eGFR) of $42 \mathrm{~mL} / \mathrm{min}(N=$ $>60 \mathrm{ml} / \mathrm{min}$ ). Action at this office visit included discontinuation of Lisinopril, increase of amlodipine to $10 \mathrm{mg}$ a.m. and $5 \mathrm{mg}$ p.m. to improve BP control, and decrease of allopurinol 150 $\mathrm{mg}$ (due to decreased kidney function), and decrease of pravastatin to $40 \mathrm{mg}$ PO daily. Fasting and 2-h basic metabolic panel (BMP), glycosylated hemoglobin $\left(\mathrm{HbA}_{1} \mathrm{c}\right)$ and serum insulin levels were ordered. At his next visit, two weeks later, FBG was $102 \mathrm{mg} / \mathrm{dL}$ and $2 \mathrm{hPPG}$ was $139 \mathrm{mg} / \mathrm{dL}$. Both of these levels were normal. Serum creatinine $(\mathrm{mg} / \mathrm{dL})$ and eGFR $(\mathrm{ml} /$ $\mathrm{min}$ ) for the corresponding periods were $1.73 / 42$ and $1.66 / 44$ respectively. The $2 \mathrm{hPP}$ serum insulin level was $126.5 \mathrm{ulU} / \mathrm{L}$. At this time, he was advised to discontinue glimepiride, switch HCTZ to chlorthalidone $25 \mathrm{mg}$ daily, increase amlodipine to $10 \mathrm{mg}$ twice daily, and potassium chloride $20 \mathrm{mEq}$ daily was added. At his third visit, six weeks later, his glucose levels for both FBG and 2 hPPG were increased. He returned to the office in late March of 2012 with a laboratory done March 1, 2012. He is no longer taking glimepiride but taking thiazide diuretic chlorthalidone $25 \mathrm{mg}$ /day to keep hypertension under control. His sitting and upright BP were $120 / 80 \mathrm{mmHg}$. FBG and $2 \mathrm{hPPG}$ decreased to $130 \mathrm{mg} / \mathrm{dL}$ and $152 \mathrm{mg} / \mathrm{dL}$, respectively' compared to those in the previous visit even though he was no longer taking the glimepiride. His fasting insulin was normal $(16.7 \mu \mathrm{lU} / \mathrm{ml})$ and his serum potassium was low $(3.4 \mathrm{mmol} / \mathrm{L})$ in both periods due to chlorthalidone. Thus potassium intake was increased to $20 \mathrm{mEq}$ twice daily and the patient was advised to increase dietary potassium. Thus here is a patient who went to a physician for treatment of hypertension. He was treated with a thiazide diuretic, beta blocker, calcium channel blocker and ACEl drugs. All of these 
antihypertensive drugs have been documented to produce hyperglycemia (Figure 1) [1,2]. He developed hyperglycemia with a random glucose level of $180 \mathrm{mg} / \mathrm{dL}(10 \mathrm{mmol} / \mathrm{L})$ and $\mathrm{HbA}, \mathrm{c} 6.2 \%$ noted in June of 2011 . Thus he was labeled to have developed Type 2 diabetes mellitus (DM) and placed on glimepiride, an oral hypoglycemic agent. Perhaps the primary care physician did not know that it is common to find hyperglycemia when a patient is treated with a thiazide diuretic, and glucose level is often reduced with correction of serum potassium. Therefore by definition, he does not have diabetes ( $2 \mathrm{hPPG}>200 \mathrm{mg} / \mathrm{dL}$ ) [5]. BP is under control and kidney function is improving. This slightly elevated glucose is clearly due to the thiazide diuretic, chlorthalidone, as evidenced by concomitant hypokalemia. His major risk factors were uncontrolled hypertension which is now under control, and decreased kidney function which is now improving. He is asymptomatic and active.

Patient \#2 - A 58 year old white male, wheelchair bound, a self-referral to AKM in November of 2011, gave an 8 to 10 ten year history of diabetes. He was treated with metformin 500 mg PO twice daily, glipizide $5 \mathrm{mg}$ PO daily, enalapril $10 \mathrm{mg}$ PO daily, indomethacin $50 \mathrm{mg} P O$ every 8 hours for gout, and Lipitor $10 \mathrm{mg} P O$ daily. The patient was also diagnosed with atrial fibrillation which was treated with digoxin $0.125 \mathrm{mg} P O$ daily and warfarin $2 \mathrm{mg} P O$ daily. Two months prior to the first office visit with this author, the patient was admitted to a local hospital with acute renal failure where oral hypoglycemic agents were discontinued and he was started on insulin. At the time of the first office visit, the patient was receiving insulin detemir (Levemir $\left.{ }^{\oplus}\right) 20 \mathrm{U}$ subcutaneously at bedtime, warfarin with dose adjusted according to INR, allopurinol $150 \mathrm{mg}$ PO daily, metoprolol $25 \mathrm{mg}$ PO BID, and sodium bicarbonate $650 \mathrm{mg}$ PO TID. Fasting laboratory results from one day prior to office visit showed glucose of $82 \mathrm{mg} /$ $\mathrm{dL}, \mathrm{BUN} 20 \mathrm{mg} / \mathrm{dL}$, serum creatinine $1 \mathrm{mg} / \mathrm{dL}, \mathrm{eGFR}>60 \mathrm{ml} /$ $\mathrm{min}$, Na $142 \mathrm{mmol} / \mathrm{L}, \mathrm{K} 4.1 \mathrm{mmol} / \mathrm{L}, \mathrm{Cl} 104 \mathrm{mmol} / \mathrm{L}, \mathrm{CO}_{2} 30.8$ $\mathrm{mmol} / \mathrm{L}, \mathrm{HbA}, \mathrm{c} 5.6 \%$, hemoglobin $11.9 \mathrm{~g} / \mathrm{dL}$ and hematocrit $35.2 \%$. His urinalysis was normal. His resting BP was 150 $160 \mathrm{mmHg}$ systolic and $100-110 \mathrm{mmHg}$ diastolic, and pulse 64 beats/min. The abdomen could not be examined for bruit because of his disability. At this visit, metoprolol was switched to atenolol $50 \mathrm{mg}$ PO daily, insulin detemir was put on hold, and chlorthalidone $12.5 \mathrm{mg}$ PO daily was prescribed to achieve BP control. He returned to the office four weeks later. On this second visit, his pulse rate was 80 beats/min and resting BP was $140 / 100 \mathrm{mmHg}$. A laboratory report, done two weeks after the first visit, without insulin or oral hypoglycemic therapy, showed FBG and 2 hPPG $131 \mathrm{mg} / \mathrm{dL}$ and $134 \mathrm{mg} / \mathrm{dL}$, respectively. His kidney function was slightly reduced with eGFR of $56.7 \mathrm{ml} / \mathrm{min}$ in both periods. $\mathrm{HbA}_{1} \mathrm{c}$ was $5.4 \%$ and average glucose was $108 \mathrm{mg} / \mathrm{dL}$. Atenolol was increased to $50 \mathrm{mg} \mathrm{PO}$ a.m., and $25 \mathrm{mg}$ PO p.m. to achieve $\mathrm{BP}$ control. All other medications remained unchanged. At the third visit in mid-March 2012, his sitting BP was normal $(110-100 / 70 / 80 \mathrm{mmHg})$ pulse rate was 58 beats/min. Most current laboratory showed FBG and 2 hPPG were $132 \mathrm{mg} / \mathrm{dL}$ and $118 \mathrm{mg} / \mathrm{dL}$, respectively. Renal function decreased further, with eGFR of $51.9 \mathrm{ml} / \mathrm{min}$ and $47.9 \mathrm{ml} / \mathrm{min}$ in fasting and $2 \mathrm{hPP}$ periods, respectively. This decrease in renal function is most likely due to chlorthalidone. Thus dosage of chlorthalidone was reduced to Monday, Wednesday and Friday.

Patient \#3 - 64 year old African-American male was referred for uncontrolled hypertension and hypokalemia. His medication consisted of diltiazem CD 360 mg PO daily, amlodipine $10 \mathrm{mg}$ PO daily, Triam/HCTZ 37.5/25 mg PO daily, and $\mathrm{KCl} 20 \mathrm{mEq}$ TID. Laboratory results are shown in Table 1. Here is a patient who developed severe hyperglycemia mimicking diabetes in 2009, but glucose levels became normal upon discontinuation of triamterene/hychlorothiazide. He continued to take potassium chloride supplements. Thus it is safe to inform the patient that he does not have diabetes now but has a risk of developing diabetes in the future because of a high insulin response.

Patient \#4-83 year old white male weighing 287 pounds and with pre-existing congestive heart failure (CHF), aortic stenosis, and aortic insufficiency with shortness of breath even with continuous oxygen therapy, and swelling of both lower extremities has been followed in the office of the corresponding author since the beginning of 2007. His treatment consisted mainly of Triam/HCTZ 37.5/25 PO daily, with intake of potassium chloride 10 to $20 \mathrm{mEq}$ PO daily. Intermittently, additional diuretics such as furosemide 20 to $40 \mathrm{mg}$ daily and metolazone 2.5 to $5 \mathrm{mg}$ PO per day supplemented his therapy. Over time, his shortness of breath and swelling of the lower extremities decreased requiring decreased dosage of diuretics until the end of 2010 when Triam/HCTZ was put on hold and metolazone was reduced to $2.5 \mathrm{mg} \mathrm{PO}$ on Tuesdays and Thursdays only. A laboratory has accompanied every office visit and serum glucose levels varied from normal to high, depending on the number of diuretics used, until 2010 when the glucose level remained consistently elevated. In September of 2010 he was placed on glipizide $5 \mathrm{mg}$ PO with lunch and dinner, but glucose levels markedly increased despite discontinuing use of diuretic(s). In mid-January of 2011, his FBG and 2hPPG were $307 \mathrm{mg} / \mathrm{dL}$ and $468 \mathrm{mg} / \mathrm{dL}$, respectively. He was started on Glargine insulin, 25 units subcutaneously after breakfast and again after dinner. Initiation of insulin treatment was followed by a steady decline of both FBG and 2hPPG to normal levels. His insulin dosage is reduced to 10 units after breakfast and dinner. In October of 2011 his $\mathrm{HbA}_{1}$ c was $5.6 \%$ and average glucose was $114 \mathrm{mg} / \mathrm{dL}$. His latest office visit in February 2012 revealed FBG and $2 \mathrm{hPPG}$ of $112 \mathrm{mg} / \mathrm{dL}$ and $101 \mathrm{mg} / \mathrm{dL}$, respectively. Summary of his glucose levels in form of lows, highs, and mean levels from 2007 to 2011 are presented in Figure 3. The $\mathrm{HbA}_{1} \mathrm{c}$, and range and mean serum creatinine 
Mandal et al. Journal of Diabetes Research and Clinical Metabolism 2012, http://www.hoajonline.com/journals/pdf/2050-0866-1-4.pdf

Table 1 - Patient \#3 - Serial Blood Glucose Levels and HbA1c

\begin{tabular}{llcc}
\hline Date & & $\begin{array}{c}\text { Glucose mg/ } \\
\text { dL (mmol/L) }\end{array}$ & HbA1C \\
\hline $\begin{array}{l}\text { 2009 } \\
\text { October 26 }\end{array}$ & Random & $186(10.3)$ & \\
November 6 & $\begin{array}{l}\text { Triam/HCTZ } \\
\text { discontinued }\end{array}$ & & \\
November 17 & Fasting & $113(6.2)$ & $6.1 \%$ \\
& 2hPP & $153(8.5)$ & \\
December 30 & Random & $147(8.1)$ & $5.9 \%$ \\
$\mathbf{2 0 1 0}$ & Fasting & $104(5.7)$ & \\
July 1 & 2hPP & $109(6)^{\star}$ & \\
$\mathbf{2 0 1 1}$ & & $119(6.6)^{*}$ & \\
September 15 & 2hPP & \\
\hline
\end{tabular}

No Diabetes $\quad$ Triam $=$ Triamterene $\quad$ HCTZ $=$ Hydrochlorothiazide ${ }^{\star} 2 \mathrm{hPP}$ lower than normal $(140 \mathrm{mg} / \mathrm{dL})$ due to high insulin response. Serum insulin $(2 \mathrm{hPP})=62.7(\mathrm{n}=0-24.9 \mu \mathrm{IU} / \mathrm{ml})$ Potential for established diabetes in years. Treatment: diet control only.

Table 2 - Patient \#4 78y WM - $\mathrm{HbA}_{1} \mathrm{c}$ and Renal Function Parameters -

\begin{tabular}{|c|c|c|c|c|c|c|}
\hline 2000 & & 2007 & 2008 & 2009 & 2010 & 2011 \\
\hline $\begin{array}{l}\mathrm{HbA}_{1} \mathrm{c}(\%) \\
(\mathrm{N}<6.5)\end{array}$ & & $6.6(1)$ & $6.7(2)$ & ND & $7.3(4)$ & $\begin{array}{c}9.8 \\
5.7^{*}\end{array}$ \\
\hline $\begin{array}{l}\text { Fasting } \\
\text { Scr }(\mathrm{mg} / \mathrm{dL})\end{array}$ & Range & $\begin{array}{l}1.1- \\
1.64 \\
(8)\end{array}$ & $\begin{array}{c}1.23- \\
1.62 \\
(8)\end{array}$ & $\begin{array}{c}1.26- \\
1.45 \\
(6)\end{array}$ & $\begin{array}{c}1.35- \\
1.69 \\
(8)\end{array}$ & $\begin{array}{r}1.40- \\
1.49 \\
(4)\end{array}$ \\
\hline$(\mathrm{N}<1.50)$ & Mean & $\begin{array}{c}(8) \\
1.44\end{array}$ & $\frac{(8)}{1.39}$ & $\frac{(6)}{1.33}$ & $\begin{array}{c}(8) \\
1.52\end{array}$ & $\begin{array}{c}(4) \\
1.44\end{array}$ \\
\hline
\end{tabular}

*3 months after Glargine insulin therapy initiated

()$=$ Number of tests $\quad \mathrm{ND}=$ Not Done $\quad \mathrm{Scr}=$ Serum Creatinine $\mathrm{N}=$ normal

levels are presented in Table 2. From Table $\mathbf{2}$ it should be noted that $\mathrm{HbA}_{1} \mathrm{c}$ is elevated until 2011, when it is reduced to normal level concomitantly with decrease of glucose levels to normal after initiation of Glargine insulin therapy. His renal function determined by serum creatinine is mildly impaired but it is non-progressive. He floridly responded to Glargine insulin with regression of hyperglycemia. He feels well and maintains normal blood glucose levels (FBG and 2hPPG) with 10 units of glargine insulin twice daily.

\section{Discussion}

This study presents four patients who were treated with thiazide diuretic and developed hyperglycemia. Two patients were treated with oral hypoglycemic agents and one with insulin detemir. Discontinuation of thiazide diuretic resulted in restoration of normoglycemia and termination of oral hypoglycemic agents. Diabetes in insulin treated patient (Patient \#2) could not be documented after discontinuation of insulin. Authors observations indicate that hyperglycemia of variable severity is common in hypertensive patients treated with diuretics, mainly thiazide diuretics. However, unlike other authors, these authors have demonstrated that hyperglycemia is reversible upon discontinuation of the diuretic as it is shown clearly in patient \#3. However, a patients glucose level may not decrease upon discontinuation of the diuretic as in patient \#4.

This patient who has developed overt diabetes, requiring insulin therapy, raises an important question: does diureticinduced hyperglycemia lead to overt diabetes? To that effect other authors have asked the question "are antihypertensive agents simply unmasking or masking diabetes" [6]? Intracellular potassium deficiency even with near normal serum potassium, is an important determining factor for hyperglycemia induced by diuretic therapy, and correction of hypokalemia using potassium supplements attenuates hyperglycemia [7].

Low serum potassium has been considered an important mechanism in the pathogenesis of diuretic induced hyperglycemia by these and other authors $[6,7]$. It is important to understand that serum potassium does not necessarily correlate with intracellular potassium stores. Therefore serum potassium may be normal but intracellular potassium deficit still persists and hence may attenuate endogenous insulin release and cause hyperglycemia. Since it is difficult to measure intracellular potassium, we have to depend on serum potassium as an index of intracellular potassium. In patient \# 4 for example, serum potassium levels varied between 4.2 and $4.4 \mathrm{mmol} / \mathrm{L}$ from 2007 to 2011 during continuous potassium supplementation and use of triamterene along with HCTZ. He still developed sustained hyperglycemia with time leading to overt diabetes and required insulin therapy to control glucose levels. A pearl of wisdom came from this patient where it was observed that control of persistent hyperglycemia with insulin therapy, markedly decreased his shortness of breath and he no longer requires oxygen therapy. He is more lively than before. To that effect, it is important to seek out mechanisms other than hypokalemia alone to explain hyperglycemia. As such, other authors have identified $\mathrm{HbA}_{1} \mathrm{c}$ (odd ratio 4.21 per $1 \%$ increment) as baseline predictor of diabetes [8]. The findings in our patient \#4 concur with the previous observation. As shown in Table 2, HbA1c in patient \#4 increased from baseline $6.6 \%$ in 2007 to $9.8 \%$ in 2011 when he developed overt diabetes.

The problem of predicting cardiovascular or renal risk associated with drug-induced hyperglycemia still remains. There are several reasons for that: 1. Diuretic, especially thiazide diuretic, is an essential therapy in hypertension and 2. Hypertension in and of itself is associated with much greater cardiovascular and renal risks thus making it difficult to distinguish them from those caused by diuretic therapy. 3 . 
Most studies are post hoc findings and were not adequately powered to assess the association between diuretic therapy and new-onset diabetes [9]. 4. New-onset diabetes was defined differently in different studies [9]. Further, comparing antihypertensive drug classes is difficult owing to differing study designs [10].

\section{Conclusion}

It is evident from all previous studies and our own observations that use of diuretics in the treatment of hypertension or CHF gives rise to hyperglycemia. Thiazide diuretics such as HCTZ or chlorthalidone more often cause hyperglycemia than other diuretics. Severity of hyperglycemia varies but generally does not exceed $200 \mathrm{mg} / \mathrm{dL}(\geq 11 \mathrm{mmol} / \mathrm{L}$ ) to call this condition established diabetes by definition. However, no prospective or long-term follow up studies are available to determine that diuretics merely cause hyperglycemia or unmask diabetes. Thus for now, diuretic-induced hyperglycemia is caused by volume and potassium depletion and treatment with potassium or reduction of the dose of diuretics reduce blood glucose levels to near normal or normal levels. However, there are exceptions to this dictum. As such occasional patients with use of multiple diuretics may give rise to symptomatic diabetes requiring insulin therapy. Except for that, no microvascular or macrovascular complications, unique for untreated diabetes, have been observed in diuretic-induced hyperglycemia.

\section{Competing interests}

The Authors declare that they have no competing interests. Author information

${ }^{2}$ Department of Veterinary Biomedical Sciences, University of Saskatchewan, Saskatoon, Canada.

\section{Publication history}

Received: 14-May-2012 Accepted: 08-June-2012

Published: 12-July-2012

\section{References}

1. Moser M. Is new onset diabetes of clinical significance in treated hypertensive patients? J Clin Hypertens 2006, 8: 126132. | Article | PubMed

2. Gurwitz JH, Bohn RL, Glynn RJ, et al Antihypertensive drug therapy and the initiation of treatment for diabetes mellitus. Ann Intern Med, 1993, 118: 273-278. | Article | PubMed

3. The ALLHAT Officers and Coordinators for the ALLHAT Collaborative Research Group. Major outcomes in high risk hypertensive patients randomized to angiotensin converting enzyme inhibitor or calcium channel blocker vs. diuretic: the antihypertensive and lipid-lowering treatment to prevent heart attack trial. JAMA 2002, 288: 2981-2997.

4. Verdecchia P, Reboldi G, Angeli F, Borgioni C, Gattobigio R, Filippucci $L$, et al.: Adverse prognostic significance of new diabetes in treated hypertensive subjects. Hypertension
2004; 43;(5.);963-9. | Article | PubMed

5. Pavkov ME, Knowler WC, Lemley KV, Mason CC, Myers BD, Nelson RG: Early renal function decline in type 2 diabetes. Clin J Am Soc Nephrol 2012; 7;(1.);78-84. | Article | PubMed

6. Padwal R, Laupacis A Antihypertensive therapy and incidence ot Type 2 diabetes. Diabetes Care 2004, 27: 247-255. | Article

7. Halderman JH, Elahi D, Anderson DK, Raizes GS, Tobin JD, Shocken D, Andres R Prevention of glucose intolerance of thiazide diuretics by maintenance of body potassium. Diabetes 1983, 32:106-111.| PubMed

8. Bakris G, Stockert J, Molitch M, Zhou Q, Champion A, Bacher P, Sowers J (STAR Investigators) Risk factor assessment for newonset diabetes: literature review. Diabetes Obes Met 2008, 11: 177-87. | Article | PubMed

9. Duarte JD, Cooper-Dehoff RM. Mechanisms for blood pressure lowering and metabolic effects of thiazide and thiazide-like diuretics. Expert Rev Cardiovasc Ther 2010, 8: 793802. | Article | PubMed Abstract | PubMed Full Text

10. Sicca DA 2004 Diuretic-related side effects: development and treatment J Clin Hypertens; 2004, 6: 532-540. | Article | PubMed 